УДК 316.422 .42

DOI 10.52575/2712-746X-2021-46-4-790-793

\title{
Дигитализация образовательного пространства вуза: дизьюнкция вместо интеграции
}

\author{
Серкина Я.И. \\ Белгородский государственный национальный исследовательский университет \\ Россия, г. Белгород, ул. Победы, д. 85 \\ E-mail: serkina_ya@bsu.edu.ru
}

\begin{abstract}
Аннотация. Проанализирована специфика дигитализации образовательного пространства вуза, как процесса внедрения в систему высшего образования современных информационных технологий, ведущего к качественному изменению образовательной среды посредством придания ей техноантропогенного характера и изменения поведенческих паттернов акторов. Сделан вывод о том, что в современных российских условиях дигитализация, которая могла бы усилить уровень интегрированности элементов образовательного пространства, вследствие непоследовательности ее реализации наращивает его дискретность и стимулирует противоречия и латентные конфликты.
\end{abstract}

Ключевые слова: образование, высшее учебное заведение, образовательное пространство, концепция дигитализации

Благодарности: исследование выполнено за счет гранта Российского научного фонда № 21-1800150.

Для цитирования: Серкина Я.И. 2021. Региональное образовательное пространство в контексте дигитализации. NOMOTHETIKA: Философия. Социология. Право, 46 (4): 790-793. DOI: $10.52575 / 2712-746 \mathrm{X}-2021-46-4-790-793$

\section{Digitalization of the University's Educational Space: Disjunction Instead of Integration}

\author{
Yana I. Serkina \\ Belgorod National Research University \\ 85 Pobeda St, Belgorod 308015, Russian Federation \\ E-mail: serkina_ya@bsu.edu.ru
}

\begin{abstract}
Annotation. The article analyzes the specifics of digitalization of the educational space of the university as a process of introducing modern information technologies into the higher education system, leading to a qualitative change in the educational environment, by giving it a technoanthropogenic character and changing the behavioral patterns of actors. The conclusion is substantiated that in modern Russian conditions, digitalization, which could increase the level of integration of the elements of the educational space, due to the inconsistency of its implementation, increases its discreteness and stimulates contradictions and latent conflicts.
\end{abstract}

Keywords: education, higher educational institution, educational space, regional university, the concept of digitalization

Acknowledgements: the research was carried out at the expense of the grant of the Russian Science Foundation No. 21-18-00150.

For citation: Serkina Ya.I. 2021. Digitalization of the University's Educational Space: Disjunction Instead of Integration. NOMOTHETIKE: Philosophy. Sociology. Law, 46(4): 793-796 (in Russian). DOI: $10.52575 / 2712-746 \mathrm{X}-2021-46-4-790-793$ 
Характерной и принципиально важной особенностью современной социальной реальности является массовое внедрение информационно-коммуникационных технологий. По мнению М.Г. Делягина, оно «кардинально меняет процесс принятия решений далеко за пределами их непосредственного воздействия, заставляя людей и коллективы действовать в условиях крайне агрессивной информационной среды» [Делягин, 2000]. Изменения нередко оказываются настолько неожиданными, что социально-гуманитарные науки зачастую оказываются не готовыми ответить на формируемые ими вызовы. К числу таких вызовов, по мнению О.Н. Яницкого, относится дигитализация. Изначально она рассматривалась в качестве инструмента для облегчения течения социальных процессов, но постепенно превратилась в способ существования социальности. Внедрение и навязчивое использование ограниченного количества «компетенций» и «протоколов» быстро вытеснило из социальных исследований и социальной практики разнообразие социальных процессов. И, как следствие, сложилось противоречие между множественными конкретными ситуациями, возникающими в обществе, и ограниченным списком мероприятий, рассматриваемых как реакция на эти ситуации. «В этом случае научная рефлексия, практическое осмысление и самоорганизация двустороннего процесса исследование - решение замещается выбором из некоторого набора готовых приёмов принятия решений» [Яницкий, 2018].

Одним из следствий своего рода запаздывания ответа на комплекс проблем, обусловленных цифровизацией и дигитализацией общества, является отсутствие единой устоявшейся концепции данного процесса в различных сферах, в том числе и в образовании, несмотря на то, что он все более определяет развитие образовательных пространств различных уровней, представляющих «совокупность образовательных систем, каждой из которых в его рамках отводится определенное место, организуемое по образу и подобию государственного устройства» [Сериков, 1997].

Процесс формирования образовательного пространства структурирован и реализуется на нескольких иерархичных уровнях: федеральном (общегосударственном), региональном (уровень субъектов РФ), образовательного учреждения и его подразделений. Региональное образовательное пространство занимает в этом ряду «срединное положение», более или менее органично соединяя в своем развитии тенденции, характерные для федерального уровня и для отдельных учреждений. Эта интегрирующая (консолидирующая) функция, казалось бы, вполне очевидная, реализуется крайне непоследовательно и противоречиво. И дигитализация во многих аспектах только усиливает эту противоречивость. Представляя собой процесс внедрения в систему высшего образования современных информационных технологий, ведущий к качественному изменению образовательного пространства посредством придания ему техноантропогенного характера и изменения поведенческих паттернов акторов, дигитализация, на первый взгляд, должна наращивать интегративные качества образовательной системы. И это во многих отношениях имеет место, что выражается в унификации требований и критериев оценки, регламентации процессов, оптимизации каналов коммуникаций. Однако практики внедрения цифровых технологий нередко ведут к появлению противоположных, дизъюнктивных по своей сути эффектов.

Во-первых, они сопровождаются не только постоянными корректировками основных нормативных документов, регулирующих процесс дигитализации образования, но изменением целей, задач, планируемых результатов, технологий реализации образовательного процесса, параметров взаимодействия акторов образовательной среды, критериев и инструментов оценки качества. Значительно меняются представления о функциях высшего образования. Нельзя не учитывать, что цифровые инновации в системе образования входят в противоречие со многими традиционными элементами этой системы, что требует непростого для субъекта познания переосмысления, казалось бы, устоявшихся представлений.

Во-вторых, по своему содержанию дигитализация системы образования - это внутренне структурированный многообразный процесс, включающий в себя множество эле- 
ментов, форм проявления. В данном случае всегда существует вероятность абсолютизировать какую-то из его сторон, превратив ее в главный критерий оценки деятельности, что, в сущности, и имеет место на практике. Обычно это чисто формальные показатели, якобы прекрасно укладывающиеся в логику «цифрового мировосприятия», но не адекватные сути образовательного процесса как процесса воспроизводства культуры специфическими способами обучения, образования и воспитания. Формализованный подход не может не вызывать негативную реакцию значительной части работников и фактически раскалывает образовательные коллективы, которые лишь в силу особенностей организации институтов образования (высокого уровня социального контроля, ограниченных возможностей рынка труда и свободы выбора) не перерастают в открытые конфликты.

В-третьих, дигитализация, выступая продолжением и развитием процесса внедрения информационных технологий (показательно, что понятие «дигитализация» digitization, оцифровка - все чаще употребляемое как в научном, так и в общественнополитическом дискурсе, интерпретируется предельно широко и употребляется в одном ряду с близкими по содержанию понятиями «информатизация» и «компьютеризация»), активно создает новую «дополненную» реальность, в которую все более перемещается образовательный процесс. Эта вынужденная «миграция» сопровождается обострением противоречия между жизненным опытом работников и предъявляемыми к ним требованиями, что формирует последовательный ряд ситуаций профессионально-жизненных затруднений и внутриличностных кризисов.

В-четвертых, в ходе дигитализации с неизбежностью обостряется противоречие между ее целями и востребованными для их достижения материально-техническими ресурсами, наблюдается непоследовательность технико-технологической перестройки пространства вуза, поскольку часто цифровые технологии внедряются без необходимой подготовки и идея цифровизации опережает развитие материально-технической базы вуза. Неадекватность ресурсов побуждает акторов образовательного пространства к имитации своей деятельности и продуцированию симулякров, которые переполняют образовательную среду, дезориентируя потребителей ее услуг.

Таким образом, дигитализация образовательного пространства вуза, реализуемая в отсутствии ясной стратегии и административно-бюрократическими методами, порождает множественные противоречия и негативные по своим следствиям риски, зачастую не интегрируя образовательное пространство, но, напротив, внося в него элементы дизъюнкции.

\section{Список литературы}

1. Братимов О.В., Горский Ю.М., Делягин М.Г., Коваленко А.А. 2000. Практика глобализации: игры и правила новой эпохи. Москва, ИНФРА-М, 344 с.

2. Яницкий О.Н. 2018. К проблеме модернизации гуманитарного знания. Социологическая наука и социальная практика, 1(21): 7-22. DOI: https://doi.org/10.19181/snsp.2018.6.1.5734

3. Сериков Г.Н. 1997. Образование: аспекты системы отражения. Курган, Изд-во «Зауралье», 464 с.

4. Лазар М.Г., 2018. Цифровизация общества, ее последствия и контроль над населением. Проблемы деятельности ученого и научных коллективов, 4 (34): 170-181.

5. Горшенина С.Н., Неясова И.А., Серикова Л.А. 2013. Поликультурное образовательное пространство как педагогический феномен. Историческая и социально-образовательная мысль, 6 : 64-69.

\section{References}

1. Bratimov, O. V., Yu. M. Gorsky, M. G. Delyagin and A. A. Kovalenko, 2000. The practice of globalization: games and rules of the new era. Moscow: INFRA-M, $344 \mathrm{p}$.

2. Yanitsky O.N. 2018. On Modernization of the Humanities, Sociologicheskaja nauka i social'naja praktika, 6 (1): 7-22. DOI: https://doi.org/10.19181/snsp.2018.6.1.5734. 
3. Serikov, G.N., 1997. Education: aspects of the reflection system. Kurgan, Publ. Zaural'e, 464 c.

4. Lazar M.G., 2018. Digitalization of Society, its Consequences and Population Control. The Problems of Scientist and Scientific Groups Aktivity, 4(34): 170-181.

5. Gorshenina S.N., I.A. Neyasova and L. A. Serikova, 2013. Multicultural educational Environment as Teaching Phenomenon. Historicalandsocial-educationalidea, 6 (22): 64-69.

Конфликт интересов: о потенциальном конфликте интересов не сообщалось. Conflict of interest: no potential conflict of interest related to this article was reported.

\section{ИНФОРМАЦИЯ ОБ АВТОРЕ}

Серкина Яна Игоревна, доцент кафедры менеджмента и маркетинга Белгородского государственного национального исследовательского университета, г. Белгород, Россия

\section{INFORMATION ABOUT THE AUTHOR}

Yana I. Serkina, Associate Professor of the Department of Management and Marketing of the Belgorod National Research University, Belgorod, Russia 